\title{
A Contribution to the Construct Validity of the Tennessee Self-Concept Scale: A Confirmatory Factor Analysis
}

\author{
Beth McGuire and Howard E. A. Tinsley \\ Southern Illinois University at Carbondale
}

Non-statistical confirmatory factor analyses of the items on the Tennessee Self-Concept Scale (TSCS) were performed on samples of 678 university students and 341 male juvenile offenders to test hypotheses regarding the internal structure of the instrument. For the college sample, good confirmation of the external and internal frames of reference postulated by Fitts (1965) were obtained, but support for the internal $\times$ external cross-classification was not obtained. No support for any of the hypotheses was found for the juvenile sample; rather, one major factor emerged. These findings are related to Super's theory of self-concept development, and implications of these findings regarding the psychometric properties of the TSCS and its use are discussed.

The Tennessee Self-Concept Scale (TSCS) is a popular research and clinical measure of selfconcept, which has enjoyed widespread use by counseling psychologists. The scale has been used to assess the psychological effects of assertion training on college students and their roommates (Wolff \& Desiderato, 1980), integration on black persons (Williams \& Byars, 1970), intestinal bypass surgery on massively obese patients (Wampler, Lauer, Lantz, Wampler, Evens, \& Madura, 1980), various academic courses on college students (Furr, 1970), and a range of counseling approaches varying from be-

APPLIED PSYCHOLOGICAL MEASUREMENT Vol. 5, No. 4, Fall 1981, pp. 449-457

(C) Copyright 1981 Applied Psychological Measurement Inc. 0146-6216/81/040449-09\$1.45 havioral counseling (Kropp, Calhoon, \& Verrier, 1971) to group counseling (Padgett \& Gazda, 1968). Studies of such psychopathological disorders as alcoholism (Gross, 1971), delinquency (Richard, Mates, \& Whitten, 1969), and psychosomatic conditions (Schwab, Harmeling, \& McGinnis, 1968) have included the TSCS. The TSCS has also been used to study more normal developmental processes, such as vocational development (Barrett \& Tinsley, 1977; Resnick, Fauble, \& Osipow, 1970).

Fitts (1965) designed the TSCS to measure five externally referenced aspects of self-concept (i.e., the moral-ethical, social, personal, physical, and family self-concept) and three internally referenced aspects of self-concept (i.e., identity, behavior, and self-satisfaction). The internal and external frames of reference form a $3 \times 5$ grid containing 15 cells. Each self-concept item on the TSCS is defined by both an internal and external referent (e.g., physical-identity).

Wiley (1974) has stressed the importance of construct validation for measures of self-concept. One important test of validity for any instrument that yields measures of multiple aspects of self-concept, such as the TSCS, is the extent to which a factor analysis of the items reveals factors that correspond to the hypothesized components (Wiley, 1974). Three factor analytic studies in which the TSCS has been factored with other instruments have been reported (Drude, 1972; Rentz \& White, 1967a; Vincent, 
1968). Several investigators (Gable, LaSalle, \& Cook, 1973; Pound, Hansen, \& Putnam, 1977; Rentz \& White, 1967b) have factored the subscales of the TSCS. These procedures, legitimate for other purposes, do not address the question of whether the internal structure of the TSCS is as conceptualized by Fitts (1965). More germane to the present investigation, Bolton (1976), Fitzgibbons and Cutler (1972), Gable et al. (1973), Lang and Vernon (1977), and Vacchiano and Strauss (1968) have analyzed the TSCS item structure. Although these investigators have collected data from a variety of types of people and have used a variety of factor analytic methods, methodological problems are apparent in each of the previous studies.

Numerous decisions are required in conducting a factor analysis (see discussions in Gorsuch, 1974; Kass \& Tinsley, 1979; Weiss, 1970, 1971). In roughly chronological order the investigator must decide (1) whether the data are of sufficient quality as to warrant factor analysis, (2) the method of factor extraction, (3) the number of factors to rotate, (4) the method of factor rotation, and (5) the interpretation of the factor structure matrix.

College students served as subjects for Gable et al. (1973) and Vacchiano and Strauss (1968). The majority of the Fitzgibbons and Cutler (1972) subjects were psychiatric inpatients together with some outpatients. Lang and Vernon (1977) used psychiatric day patients aged 17 to 65 years old. Bolton (1976) used a heterogeneous group of rehabilitation clients. Despite the diversity of the subjects, one problem with all of the previous studies is that none of the investigators tested their correlation matrix to ascertain whether it contained sufficient common variance to justify factor analysis (see Kass \& Tinsley, 1979). Consequently, there is no evidence that these correlation matrices differed significantly from correlation matrices generated from random data. This is of concern because Armstrong and Soelberg (1968) have demonstrated that it is possible to produce interpretable factors by factor analyzing a data matrix of random numbers. Moreover, the sample sizes in these studies varied from 125 (Gable et al., 1973) to 312 (Bolton, 1976), yielding a subjects-to-variables ratio of 3.5 to 1 , at best. Under such circumstances the generalizabilty of the results is questionable.

Problems also exist with the method of factor extraction and the decision regarding the number of factors to rotate in the previous studies. Fitzgibbons and Cutler (1972), Gable et al. (1973), and Vacchiano and Strauss (1968) performed principal components analyses. Because principal components analysis assumes an instrument has perfect reliability, this represents an inappropriate choice of factor extraction method. Gable et al. (1973), Lang and Vernon (1977), and Vacchiano and Strauss (1968) used the Guttman criterion to determine the number of factors and rotated 22 to 30 factors. Because of the large sample sizes required for factor analysis, however, the Guttman criterion tends to yield a large number of trivial factors. This is especially true when items are factor analyzed. In fact, Vacchiano and Strauss (1968) eliminated two factors as uninterpretable for unspecified reasons. Gable et al. (1973) eliminated seven factors, and Lang and Vernon (1977) omitted two for lacking at least two interpretable factor loadings. Fitzgibbons and Cutler (1972) used Cattell's scree test and rotated six factors, whereas Bolton (1976) extracted and rotated a theoretically predetermined number of factors (two, three, five).

Two classes of factor rotation methods are available-orthogonal methods, which yield uncorrelated factors, and oblique rotations, which yield correlated factors. Despite the fact that Fitts (1965) designed the TSCS subscales to be correlated, Fitzgibbons and Cutler (1972), Lang and Vernon (1977), and Vacchiano and Strauss (1968) used an orthogonal varimax rotation procedure. More appropriately, Gable et al. (1973) used oblimax and Bolton (1976) used oblimin.

Finally, a cutoff of .40 was established by Gable et al. (1973) and Vacchiano and Strauss (1968) for the factor loadings to be included in 
the interpretation of the factor. Bolton (1976), Fitzgibbons and Cutler (1972), and Lang and Vernon (1977) used a cutoff of .30, a more appropriate criterion when the variables are items with poor reliability. Such a criterion results in interpreting those items having $9 \%$ or more common variance with the factor.

Generally, none of the previous studies supports Fitts's (1965) theorized 15 aspects of selfconcept. Gable et al. (1973) and Vacchiano and Strauss (1968) found more support for the external frames of reference than the internal. Bolton's (1976) analysis of the 90 self-concept items found some support for the satisfaction subscale as well as the physical, family, and, to a lesser degree, social selves. All agreed that the TSCS appeared to be a complex measure of self-concept but that it did not factor neatly into the aspects of self-concept theorized by Fitts (1965).

Gorsuch (1974) and Kass and Tinsley (1979) have recommended the use of confirmatory or hypothesis-testing factor analytic methods for extant instruments, especially those developed on the basis of an explicit theoretical structure such as TSCS. Such an analysis should provide more definitive information regarding the internal structure of the TSCS, especially considering the many methodological problems apparent in the previous research. This study reports the results of nonstatistical confirmatory factor analyses performed on data obtained from two samples of respondents.

\section{Subjects}

\section{Method}

Samples of 678 university students and graduates and 341 male juvenile offenders were studied. The university sample consisted primarily of undergraduates enrolled at two major universities but also included graduate students and 82 university-educated persons, the latter sampled from across the nation. Respondents in this sample ranged in age from 17 through their 30s. Approximately half the sample was male and approximately $30 \%$ were enrolled in psy- chologically oriented self-help programs of some type. The TSCS was administered according to standard instructions in the manual by seven experimenters in the context of nine different investigations. In any research in which the TSCS was administered both prior to and after an experimental manipulation, the data from the premanipulation administration were used.

The boys in the juvenile offender sample completed the TSCS under the supervision of one research team, following standard instructions. The TSCS scores were obtained shortly after admission to a forestry camp and prior to any treatment there. The boys in this sample ranged in age from 12 to 18 .

\section{Instrument}

As noted above, the TSCS yields scores on 15 aspects of self-concept, each of which has an internal and external referent.(Fitts, 1965). In developing the TSCS, items were obtained from earlier self-concept measures and from written self-descriptions (Fitts, 1965). To test their sampling validity, the items were submitted to seven clinical psychologists who were instructed to classify each item in one of the 15 cells formed by the cross-classification of the internal by external frames of reference. Any item for which agreement was not unanimous was discarded. The final form of the TSCS contains 90 self-concept items, 6 in each cell. Half of the items are worded so that endorsement indicates low selfesteem and the other half are worded so that endorsement indicates high self-esteem. In addition, the TSCS contains 10 self-criticism items taken from the L-Scale of the Minnesota Multiphasic Personality Inventory (MMPI). All items are presented in a 5-point Likert format.

\section{Analysis}

Although identical procedures were used, the data from the two samples were analyzed separately. First, scores for all negatively worded items were reversed so that a low score on all 
items reflected a positive self-concept. A Pearson product-moment correlation matrix was then calculated for all 100 items and Bartlett's (1950) test was performed to determine whether the correlation matrix contained significant nonrandom variance. Both matrices were found to differ significantly from a matrix of random data.

Fitts (1965) has postulated a specific latent structure underlying the TSCS. Although it is appropriate to perform an exploratory factor analysis as the previous investigators have done to determine the most parsimonious factor structure of the TSCS, an adequate test of Fitt's (1965) postulated factor structure requires use of a hypothesis-testing method of factor analysis. Therefore, the method of correlated multiple group analysis (MGA) recommended by Gorsuch (1974, pp. 74-78) and Kass and Tinsley (1979) was used. Multiple group factor analysis is a method of nonstatistical factor analysis in which a theoretical model is defined in terms of how each variable should load on the postulated factors. In the correlated multiple group analysis performed, each factor was defined as the sum of the standard scores for the variables postulated to comprise the factor. Squared multiple correlations based on the variables hypothesized to form a factor were used as communalities in the analysis. The factor structure matrix was obtained by correlating the original variable scores with the multiple group factor scores. The resulting factors were not rotated.

Three alternative factor structures were hypothesized for the TSCS data. All three factor structures were expected to have a 10 -item factor composed of the self-criticism items. The cell hypothesis postulated a factor structure of 16 factors, 15 factors of six items each representing the cells of the $3 \times 5$ grid, plus the self-criticism factor. The column hypothesis postulated six factors consisting of the self-criticism factor and 18-item factors representing the physical, moralethical, personal, family, and social selves. Finally, the row hypothesis postulated a four-factor solution consisting of the 10 -item self-criti- cism factor and 30-item identity, behavior, and self-satisfaction factors.

Interpretation of the MGA requires comparisons of the hypothesized and observed factor structures. Since Fitts's (1965) conceptualization assigns all the variance of an item to a single scale, it was necessary to develop criteria for assigning the items to the various factors resulting from the MGA. Each item was assigned to the factor on which it loaded the highest, provided that the absolute value of the factor loading was $\geqslant .30$. Items with absolute factor loading $\leqslant .29$ were not assigned to any factor.

\section{Results}

\section{University Sample}

Analysis of the factor loadings for the college sample resulted in the assignment of only 22 of the 100 items to the factors specified by the cell hypothesis (see Table 1).' Instead of the expected 6 items on the first 15 factors and 10 on the last, this analysis resulted in a factor solution in which 56 items were assigned to the first factor and from 0 to 8 items were assigned to the remaining factors. In contrast, 80 of the 100 items were assigned to the factor designated by the column hypothesis (see Table 2). Fourteen of the 18 hypothesized items and 2 nonhypothesized items were assigned to the moral-ethical factor. To the personal factor were assigned 15 hypothesized items and 3 nonhypothesized items. Assigned to the family factor were 13 hypothesized items and 0 nonhypothesized items and to the social factor 14 hypothesized items and 2 nonhypothesized items. The self-criticism factor had 8 hypothesized and 0 nonhypothesized items.

For the row hypothesis, the factor-loading matrix resulted in the assignment of 79 items to the

\footnotetext{
'Tables specifying the factor structure hypothesized in the cell, column, and row hypotheses and the factor structures obtained in testing these hypotheses with the data from the university and juvenile delinquent samples are available from the first author upon request.
} 
Table 1

Number of Items Assigned to Factors in Multiple Group Analyses of Cel1 Hypothesis

\begin{tabular}{|c|c|c|}
\hline Hypothe & University Sample & Juvenile offender Sample \\
\hline
\end{tabular}

Factors

Hypothesized Hypothesized Hypothesized Hypothesized

Physical Identity

Moral Identity

Personal Identity

Family Identity

Social Identity

Physical Satisfaction 2

Moral Satisfaction 1

Personal Satisfaction 2

Family Satisfaction 2

Social Satisfaction 0

Physical Behavior

Moral Behavior

Personal Behavior

Family Behavior

Social Behavior

Self-criticism

Total I tems

$\begin{array}{rr}5 & 51 \\ 0 & 2 \\ 1 & 7 \\ 1 & 1 \\ 2 & 2 \\ 2 & 0 \\ 1 & 0 \\ 2 & 0 \\ 2 & 0 \\ 0 & 0 \\ 3 & 6 \\ 1 & 2 \\ 1 & 1 \\ 0 & 1 \\ 1 & 1 \\ 0 & 0 \\ 22 & 74\end{array}$

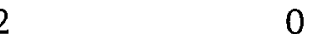

3

10

20

0

1

2

0

3

60

0

0

2

0

7

18

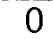

0

10

1

0

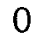

13

0

0

19

0

0

0

16

0

23

82 hypothesized factors (see Table 3). Assigned to the identity factor were 26 hypothesized and two nonhypothesized items. The satisfaction factor had 22 hypothesized and four nonhypothesized items assigned to it. Assigned to the behavior factor were 22 hypothesized items and zero non-

Table 2

Number of Items Assigned to Factors in Multiple Group Analyses of Column Hypothesis

\begin{tabular}{|c|c|c|c|c|}
\hline \multirow{3}{*}{$\begin{array}{c}\text { Hypothesized } \\
\text { Factors }\end{array}$} & \multicolumn{2}{|c|}{ University Sample } & \multicolumn{2}{|c|}{ Juvenile of fender Sample } \\
\hline & & Not & & Not \\
\hline & Hypothesized & Hypothesized & Hypothesized & Hypothesized \\
\hline Physical Self & 14 & 2 & 4 & 5 \\
\hline Moral Self & 16 & 2 & 6 & 8 \\
\hline Personal Self & 15 & 3 & 7 & 4 \\
\hline Family Self & 13 & 0 & 2 & 2 \\
\hline Social Self & 14 & 2 & 2 & 7 \\
\hline Self-Criticism & 8 & 0 & 4 & 26 \\
\hline Total Items & 80 & 9 & 25 & 52 \\
\hline
\end{tabular}


Table 3

Number of Items Assigned to Factors in Multiple Group Analyses of Row Hypothesis

\begin{tabular}{|c|c|c|c|c|}
\hline \multirow{2}{*}{$\begin{array}{c}\text { Hypothesized } \\
\text { Factors }\end{array}$} & \multicolumn{2}{|c|}{ University Sample } & \multicolumn{2}{|c|}{ Juvenile offender Sample } \\
\hline & Hypothesized & $\begin{array}{c}\text { Not } \\
\text { Hypothesized }\end{array}$ & Hypothesized & $\begin{array}{c}\text { Not } \\
\text { Hypothesized }\end{array}$ \\
\hline Identity & 26 & 2 & 8 & 4 \\
\hline Satisfaction & 22 & 4 & 9 & 20 \\
\hline Behavior & 22 & 2 & 0 & 8 \\
\hline Self-Criticism & 9 & 0 & 5 & 41 \\
\hline Total Items & 79 & 8 & 22 & 73 \\
\hline
\end{tabular}

hypothesized items. Nine hypothesized items and zero nonhypothesized items were assigned to the self-criticism factor.

\section{Juvenile Offender Sample}

Analysis of the juvenile offender factor-loading matrices resulted in the assignment of 18 , 25 , and 22 items to the factor designated in the cell, column, and row hypotheses, respectively (see Tables 1, 2, and 3). In each instance the selfcriticism factor had the most assigned items. In the analysis of the cell hypothesis, 7 of the 16 factors garnered all the highest loadings. Five factors had between 13 and 30 items each, one factor had two items, and another had one. The six factors designated in the column hypothesis were assigned 9, 14, 28, 4, 9, and 30 items instead of the hypothesized distribution of 18 for each column factor and $\mathbf{1 0}$ for the self-criticism factor. For the row hypothesis, the four factors were assigned $12,29,8$, and 46 items, respectively.

\section{Discussion}

The MGA performed on the data obtained from the university sample revealed little support for the cell hypothesis in that only $22 \%$ of the items were assigned as expected. That 16 of the pairwise correlations between the factors were over .70 suggests that many of the factors shared a substantial proportion of common vari- ance. The finding that no items were assigned to three of the hypothesized factors is further evidence that the cell hypothesis resulted in the extraction of too many factors to represent accurately the latent structure of the data. On the other hand, moderate confirmation was observed for the row and column hypotheses. The analyses resulted in the assignment of $79 \%$ (row hypothesis) and $80 \%$ (column hypothesis) of the items to the hypothesized factors. Since only nine items $(10 \%)$ and eight items $(9 \%)$, respectively, were incorrectly assigned in testing the column and row hypotheses, this confirmation is even stronger than it might appear. The remaining items were not assigned to any factor.

It is important to note that the data for the university sample could be factored into external referents (columns) and into internal referents (rows) but not into the cells formed by the cross-classification of the external and internal referents. An item such as "I have a healthy body," for example, loaded on the physical factor in the column analysis and on the identity factor in the row analysis but not on the physical-identity factor in the cell analysis. Two factors have most likely contributed to this situation. First, it must be remembered that the unit of analysis in this research was the single TSCS item. Given the notoriously poor reliability of the typical item, it seems likely that the common variance shared by the six items in each cell may not have been sufficient to be detected by the MGA in the midst of the error variance. 
A related consideration is that the reliable variance of an item may be fractionated in different ways. When testing the row hypothesis, each item supposedly shared variance in common with the 29 other items in the row and with 6 items in each of the other two rows. When testing the column hypothesis, each item supposedly shared variance in common with the 17 other items in the column and with 6 items in each of the other four columns. Under such circumstances, significant factor loadings were typically observed for the postulated row and column. When testing the cell hypothesis, however, each item supposedly showed variance in common with 5 other items in the same cell and with 6 other items in each of 6 different cells. This essentially equal allocation of common variance across 7 different cells created a situation in which each item could be expected to load on many different factors with approximately equal weight.

If this explanation has merit, an obvious conclusion is that the method of correlated multiple group factor analysis used in this investigation provided an inadequate test of the cell hypothesis. Bentler and Lee (1979) have recently suggested an alternative method of confirmatory analysis, which is applicable to situations such as this, and Tucker's (1964) three-mode factor analysis offers a method for exploratory analysis of such data. Given the possibility that the results for the cell hypothesis are due to inadequacies in the method of analysis, the use of Bentler and Lee's (1979) and Tucker's (1964) methods of analysis should be considered in future research on this issue.

For the juvenile offender sample, none of the hypothesized factor structures were confirmed. In each analysis, fewer than $25 \%$ of the items were assigned to the hypothesized factors, thereby providing strong evidence that the factor structure postulated by Fitts (1965) did not exist in these data. Three possible explanations of these results deserve consideration. First, there are several possible reasons why the TSCS results of the juveniles may be invalid. One possibility is that the juvenile offenders may not have taken the group-administered TSCS seriously. Since incarcerated juveniles are often poorly educated and the TSCS requires a sixth-grade reading level, it is also possible that a significant portion of the boys answered at random due to poor reading ability. Still another possibility is that the juvenile offenders may have used the scale improperly. To investigate the possibility of random responding or response bias, five protocals were selected at random. Analysis of the pattern of responses indicated that these five tended to use the completely false category close to $50 \%$ of the time, regardless of whether the item was a positively or negatively worded selfconcept item or a self-criticism item (see Table 4). The results of this ex-post facto analysis seem to be more consistent with an interpretation of response bias than random responding.

The second possibility is that the differentiation inherent in the juvenile offender's conceptualization of self may differ significantly

\section{Table 4}

Percentage of Responses in each Response Category for Five Randomly Selected Juvenile offenders

\begin{tabular}{lccc}
\hline & \multicolumn{2}{c}{ Self-Concept Items } & Negatively \\
\cline { 2 - 4 } Response & $\begin{array}{c}\text { Positively } \\
\text { Worded }\end{array}$ & $\begin{array}{c}\text { Nelf-Criticism } \\
\text { Worded }\end{array}$ & $\begin{array}{c}\text { Items } \\
\text { Completely true }\end{array}$ \\
Mostly true & 6 & 21 & 12 \\
Partly true, partly false & 10 & 5 & 10 \\
Mostly false & 17 & 11 & 16 \\
Completely false & 46 & 16 & 18 \\
\hline
\end{tabular}


from that of the college students. Super, Starishevsky, Matlin, and Jordaan (1963) believe that vocational self-concept does not begin to crystallize until about age 14 . The years from 14 to 18 are characterized by the development of a general idea of an appropriate occupational field. More specific work preferences are formed during the "specification" stage, which generally occurs from 18 to 21 years of age, the ages of most of the university sample. Barrett and Tinsley (1977) report that specification of self-concept is a necessary prerequisite to clarification of vocational choice.

Since the juveniles ranged in age from 12 to 18 , they can be conceptualized as forming two psychologically different populations. The older subgroup (14 to 18 years old) may have begun the process of self-concept differentiation, while the 12- to 14-year olds may still be struggling with the confusion and uncertainty characteristic of young persons in their early teens. Furthermore, Fitts and Hamner (1969) concluded that juvenile delinquents were more conflicted, confused, and variable in their self-concepts than their nondelinquent peers. Thus, the juvenile offender sample may represent a group that has a relatively undifferentiated self-concept, a possibility antithetical to the structure of self-concept postulated by Fitts (1965). This interpretation is consistent with the finding that most of the items in the juvenile offender data loaded on a few factors.

The third possibility is suggested by the fact that in all three analyses the hypothesized selfcriticism scale garnered most of the items. The L-Scale of the MMPI is said to detect defensiveness. Juvenile offenders are described clinically as defensive. It may be that their responses are more a measure of defensiveness than self-concept.

The implications of these results for the use of the TSCS as a counseling instrument depend upon the client's group membership. For university students, the standard interpretation offered in the TSCS manual for the row and column scores appears justified. Analysis of the cell scores should be discouraged, however, and users are cautioned to remember that, as the manual states, the subscales are not independent.

Further research is necessary to determine whether the TSCS is appropriate for use with juvenile offenders in the 12- to 18-year age range. The present results suggest that use of the TSCS with this population is inappropriate due to defensiveness or biased responding patterns. If the respondent has at least a sixth-grade reading level and the TSCS is individually administered, it is possible that the results may accurately reflect the degree of differentiation of the individual's seif-concept. Even under those conditions, however, it may be that most juvenile offender's self-concepts are too undifferentiated to warrant the use of such fine-grained aspects of self-concept as the row and column scores. With such clients the total and self-criticism scores may still provide useful information about the individual's self-esteem and guardedness. Continued use of the TSCS with juvenile offenders is risky, however, until research bearing on the possibilities discussed in this paper is available.

\section{References}

Armstrong, J. S., \& Soelberg, P. On the interpretation of factor analysis. Psychological Bulletin, 1968, 70. 361-364.

Barrett, T. C., \& Tinsley, H. E. A. Vocational selfconcept crystallization and vocational indecision. Journal of Counseling Psychology, 1977, 24, 301-307.

Bartlett, M. W. Tests of significance in factor analysis. British Journal of Psychology, 1950, 3, 77-85.

Bentler, P. M., \& Lee, S. A statistical development of three-mode factor analysis. British Journal of Mathematical and Statistical Psychology, 1979, 32, 87-104.

Bolton, B. Factorial validity of the Tennessee SelfConcept Scale. Psychological Reports, 1976, 39. 947-954.

Collins, H. A., \& Burger, G. K. The self-concept of adolescent retarded students. Educable and Trainable Mental Retardation, 1970, 5, 23-30.

Drude, K. P. A study of the construct validity of selfconcept measures. Unpublished doctoral dissertation, University of Illinois, 1972. 
Fitts, W. H. Manual for Tennessee (Department of Mental Health) Self-Concept Scale. Nashville TN: Counselor Recordings and Tests, 1965.

Fitts, W. H., \& Hamner, W. T. Self-concept and delinquency (Studies on Self-Concept Monograph No. I). Nashville TN: Counselor Recordings and Tests, 1969.

Fitzgibbons, D. J., \& Cutler, R. The factor structure of the Tennessee Self-Concept Scale among lowerclass urban psychiatric patients. Journal of Clinical Psychology, 1972, 28, 184-186.

Furr, H. B. Influences of a course in speech communication on certain aspects of the self-concept of college freshmen. Speech Teacher, 1970, 19. 26-31.

Gable, R. K., LaSalle, A. J., \& Cook, K. E. Dimensionality of self-perception: Tennessee Self-Concept Scale. Perceptual and Motor Skills, 1973, 36. $551-560$.

Gorsuch, R. L. Factor analysis. Philadelphia: W. B. Saunders, 1974.

Gross, W. F. Self-concept of alcoholics before and after treatment. Journal of Clinical Psychology, 1971, 27, 539-541.

Kass, R. A., \& Tinsley, H. E. A. Factor analysis. Journal of Leisure Research, 1979, 11, 120-138.

Kropp, H., Calhoon, B., \& Verrier, R. Modification of the self-concept of emotionally disturbed children by covert reinforcement. Behavior Therapy. 1971, 2, 201-204.

Lang, R. J., \& Vernon, P. E. Dimensionality of perceived self: The Tennessee Self-Concept Scale. British Journal of Social and Clinical Psychology. 1977, 16, 363-371.

Padgett, H. G., \& Gazda, G. M. Effects of group guidance and group counseling on the self-concept and professional attitude of prospective teachers. SPATE, 1968, 6, 42-49.

Pound, R. E., Hansen, J. C., \& Putnam, B. A. An empirical analysis of the Tennessee Self-Concept Scale. Educational and Psychological Measure. ment, 1977, 37, 545-551.

Rentz, R. R., \& White, W. F. Congruence of the dimensions of self-as-object and self-as-process. Journal of Psychology, 1967, 67, 277-285. (a)

Rentz, R. R., \& White, W. F. Factors of self perception in the Tennessee Self-Concept Scale. Perceptual and Motor Skills, 1967, 24, 118. (b)

Resnick, H., Fauble, M. L., \& Osipow, S. H. Vocational crystallization and self-esteem in college students. Journal of Counseling Psychology, 1970, 17, 465-467.

Richard, W. C., Mates, C. G., \& Whitten, L. Personality traits and attitudes of adolescent girls with behavior disorders. Correctional Psychiatry and Journal of Social Therapies, 1969, 15, 34-44.
Schwab, J. J., Harmeling, J. D., \& McGinnis, N. H Anxiety, self-concept, and body image: Psychosomatic corrections: I. A preliminary report. Proceedings of the Fourth World Congress in Psychiatry, 1968, 1966 (Part 4), 2715-2717.

Super, D. E., Starishevsky, R., Matlin, N., \& Jordaan, J. P. Career development: Self-concept theory. New York: College Entrance Examination Board, 1963.

Tucker, L. R. The extension of factor analysis to three-dimensional matrices. In N. Frederiksen \& H, Gulliksen (Eds.), Contributions to mathematical psychology. New York: Holt, Rinehart, \& Winston, 1964.

Vacchiano, R. B., \& Strauss, P. S. The construct validity of the Tennessee Self-Concept Scale. Journal of Clinical Psychology, 1968, 24, 323-326.

Vincent, J. An exploratory factor analysis relating to the construct validity of self-concept labels. Educational and Psychological Measurement, 1968, 28, 915-921.

Wampler, R. S., Lauer, J. B., Lantz, J. B., Wampler, K. S., Evens, M. G., \& Madura, J. A. Psychological effects of intestinal bypass surgery. Journal of Counseling Psychology, 1980, 27, 492-499.

Weiss, D. J. Factor analysis and counseling research. Journal of Counseling Psychology, 1970, 17, 477-485.

Weiss, D. J. Further considerations in applications of factor analysis. Journal of Counseling Psychology. $1971,18,85-92$.

Williams, R. L., \& Byars, H. The effect of academic integration on the self-esteem of southern Negro students. Journal of Social Psychology, 1970, 80. 183-188.

Wiley, R. C. The self-concept (Vol. I): A review of methodological considerations and measuring instruments. Lincoln NB: University of Nebraska Press, 1974.

Wolff, J., \& Desiderato, O. Transfer of assertiontraining effects to roommates of program participants. Journal of Counseling Psychology, 1980, 27, 484-491.

\section{Acknowledgments}

Gratitude is expressed to Fred Ribich for consultation regarding the use of computer programs and to Tom Barrett, Laura Brown, Ken Harwood, Mike McShane, Dick Miller, Ken Ralph, and Mark Van Tuinen for making their data available for analysis.

\section{Author's Address}

Send requests for reprints or further information to Beth McGuire, 518 Mill Street, Worcester MA 01602. 